The University of San Francisco

USF Scholarship: a digital repository @ Gleeson Library | Geschke Center

Nursing and Health Professions Faculty Research and Publications

School of Nursing and Health Professions

2013

\title{
People Who Inject Drugs, HIV Risk, and HIV Testing Uptake in Sub-Saharan Africa
}

\author{
A K. Asher \\ J A. Hahn \\ Marie-Claude Couture \\ University of San Francisco, mcouture@usfca.edu \\ KMaher \\ Page
}

Follow this and additional works at: http://repository.usfca.edu/nursing_fac

Part of the Nursing Commons, and the Public Health Commons

\section{Recommended Citation}

Asher AK, Hahn JA, Couture MC, Maher K, Page K. People Who Inject Drugs, HIV Risk, and HIV Testing Uptake in Sub-Saharan Africa. Journal of the Association of Nurses in AIDS Care, Volume 24, Issue 6, e35 - e44. doi: 10.1016/j.jana.2012.09.003

This Article is brought to you for free and open access by the School of Nursing and Health Professions at USF Scholarship: a digital repository @ Gleeson Library | Geschke Center. It has been accepted for inclusion in Nursing and Health Professions Faculty Research and Publications by an authorized administrator of USF Scholarship: a digital repository @ Gleeson Library | Geschke Center. For more information, please contact repository@usfca.edu. 


\title{
People who Inject Drugs, HIV Risk, and HIV Testing Uptake in Sub-Saharan Africa
}

\author{
Alice K. Asher, RN, MS, Judith A. Hahn, PhD, Marie-Claude Couture, PhD, Kelsey Maher, \\ BA, and Kimberly Page, PhD \\ Alice K. Asher, RN, MS, is a Clinical Nurse Specialist, Department of Epidemiology and \\ Biostatistics, and a Doctoral student, Department of Community Health Systems, School of \\ Nursing, University of California San Francisco, San Francisco, California, USA. Judith A. Hahn, \\ $\mathrm{PhD}$, is an Associate Professor, Department of Medicine, San Francisco General Hospital, \\ University of California San Francisco, San Francisco, California, USA. Marie-Claude Couture, \\ $\mathrm{PhD}$, is a Post-doctoral student, Department of Epidemiology and Biostatistics, University of \\ California San Francisco, San Francisco, California, USA. Kelsey Maher, BA, is a Research \\ Assistant, Department of Epidemiology and Biostatistics, University of California San Francisco, \\ San Francisco, California, USA. Kimberly Page, PhD, is a Professor in Residence, Department of \\ Epidemiology and Biostatistics, University of California San Francisco, San Francisco, California, \\ USA
}

\section{Abstract}

Dramatic rises in injection drug use (IDU) in sub-Saharan Africa account for increasingly more infections in a region already overwhelmed by the HIV epidemic. There is no known estimate of the number of people who inject drugs (PWID) in the region, or the associated HIV prevalence in PWID. We reviewed literature with the goal of describing high-risk practices and exposures in PWID in sub-Saharan Africa, as well as current HIV prevention activities aimed at drug use. The literature search looked for articles related to HIV risk, injection drug users, stigma, and HIV testing in sub-Saharan Africa. This review found evidence demonstrating high rates of HIV in IDU populations in sub-Saharan Africa, high-risk behaviors of the populations, lack of knowledge regarding HIV, and low HIV testing uptake. There is an urgent need for action to address IDU in order to maintain recent decreases in the spread of HIV in sub-Saharan Africa.

\section{Keywords}

HIV risk; HIV testing; injection drug use; stigma; sub-Saharan Africa

\begin{abstract}
It has been reported that $10 \%$ of new HIV infections are the result of injection drug use (IDU; Joint United Nations Programme on HIV/AIDS [UNAIDS], 2007). In Eastern European countries and in some parts of South and Southeast Asia, the proportion of new HIV infections resulting from IDU is estimated to be as high as 75\%-80\% (France de Bravo et al., 2008). Excluding sub-Saharan African countries, IDU accounts for as much as $30 \%$ of new HIV infections worldwide (Mathers et al., 2008). Although IDU is widely implicated in HIV transmission, little research in sub-Saharan Africa has focused on this issue. Despite this, reports indicate that IDU is increasing in the region (Mathers et al., 2008). Moreover,
\end{abstract}

\footnotetext{
Copyright $@ 2012$ Association of Nurses in AIDS Care

Disclosures: The authors report no real or perceived vested interests that relate to this article (including relationships with pharmaceutical companies, biomedical device manufacturers, grantors, or other entities whose products or services are related to topics covered in this manuscript) that could be construed as a conflict of interest.
} 
IDU is associated with high sexual risk, linking people who inject drugs (PWID) to the wellestablished HIV epidemic in Africa. Although most HIV infections in the region occur as a result of unprotected heterosexual sex and mother-to-child transmission, current high-risk trends in IDU and few services targeted to IDU position this mode of transmission to become a significant threat in a region that is over burdened by HIV. While data available on IDU are sparse, evidence has suggested that PWID engage in high-risk injection and sexual exposures, and have high rates of HIV infection (Reid, 2009). Low HIV testing uptake and lack of knowledge of the risks associated with injecting drugs may also contribute to the emerging problem. We present a review of IDU in sub-Saharan Africa as well as a discussion of HIV risk, HIV prevalence, and HIV testing uptake in this population.

IDU is a significant contributing factor to new HIV infections in many parts of the world, including Eastern Europe, South America, and East and Southeast Asia (Mathers et al., 2008; Williams et al., 2007), and has been dramatically rising in sub-Saharan Africa in the past 10-15 years (Affinnih, 2002). Trends in IDU in recent years in Africa suggest that by 2015, $0.08 \%$ of the East African population, 0.19\% of the East-Central African, and 0.24\% of the Southern African populations will inject heroin. This nears, and may surpass, rates found in the United States, where heroin use appears to have stabilized at around $0.2 \%$ (United Nations Office for Drug Control and Crime Prevention [UNODCP], 2011). By comparison, the prevalence of opiate injection use in Eastern Europe, the highest in the world, is estimated to be between $0.8 \%$ and $1.0 \%$ (UNODCP, 2011).

Despite the rapid rise in IDU, targeted prevention and care services have not grown in proportion (Mathers et al., 2010). In the United States, more than 13,000 specialized drug treatment centers provide services to PWID in addition to other forms of inpatient and outpatient treatment programs, but in sub-Saharan Africa, less than $1 \%$ of drug users have access to treatment services (Mathers et al., 2010). The World Health Organization (WHO), UNODCP, and UNAIDS (2008) have recommended a comprehensive package of nine interventions to decrease HIV risks to PWID: (a) syringe exchange programs (SEPs); (b) opioid substitution therapy and other drug treatment; (c) HIV testing and counseling; (d) provision of antiretroviral therapy (ART) for people living with HIV (PLWH); (e) prevention and treatment of sexually transmitted infections; (f) condom programs for PWID and their sexual partners; (g) targeted information, education, and communication for PWID and their sexual partners; (h) vaccination, diagnosis, and treatment of viral hepatitis; and (i) prevention, diagnosis, and treatment of tuberculosis. However, the region continues to be unprepared to address HIV risks related to IDU. Lack of knowledge about the risks related to injecting, lack of targeted HIV prevention messaging, and stigmatization contribute to preventable risks taken by PWID (Needle, Kroeger, Belani, \& Hegle, 2006). Moreover, lack of access to sterile injecting equipment makes HIV prevention difficult, even when PWID have proper knowledge of transmission prevention (Beckerleg, Telfer, \& Sadiq, 2006; Reid, 2009).

Risks encountered by PWID are compounded by a lack of HIV testing uptake. HIV testing not only informs serostatus, letting individuals make conscious choices to protect themselves, their partners, and their children, pre- and post-test counseling also provide HIV education and individualized risk reduction counseling, even for people who are not infected with HIV (Hendriksen et al., 2009). In addition, HIV testing helps engage HIV-infected people in early care and treatment, which can reduce HIV-related morbidity and mortality and reduce transmission and incidence (Montaner et al., 2010). This is especially true when counseling is a part of the testing process, providing the patient with education about transmission and prevention in addition to giving information about HIV status (Meiberg, Bos, Onya, \& Schaalma, 2008). Unfortunately, HIV testing is not a common practice for PWID in sub-Saharan Africa (Table 1; McCurdy, Ross, Kilonzo, Leshabari, \& Williams, 
2006; Meiberg et al., 2008; Williams et al., 2007; Williams et al., 2009). Although it is difficult to quantify the proportion of PWID who are tested for HIV throughout the world, countries in Western Europe report the highest proportion of PWID with HIV on ART (89\% coverage of PWID who need ART; Mathers et al., 2010). Countries in Eastern Europe report the lowest ART coverage, with less than $1 \%$ of PWID with HIV accessing necessary medications (Mathers et al., 2010). Testing identifies infection and is a first step to engaging patients in HIV care and the associated counseling that can decrease transmission risk.

There is some evidence that PWID in sub-Saharan Africa do not understand the relationship between drug use and HIV, nor do they know the severity of the risks of some injection practices that are common in the region (Bisika, Konyani, Chamangwana, \& Khanyizira, 2008; Dahoma et al., 2006). Moreover, PWID in sub-Saharan Africa are frequently linked with high sexual risk, including low rates of condom use and transactional sex practices (Parry \& Pithey, 2006; Reid, 2009; Timpson et al., 2006). While lack of knowledge of the risks related to IDU may contribute to lack of testing uptake, this cannot entirely account for the low prevalence of HIV testing in PWID. Mass campaigns regarding the sexual roots of HIV transmission predominate, potentially obscuring awareness of injection risk. Other factors are also likely to influence decisions to be tested. Stigma, which has been implicated in poor testing uptake for PWID in other regions, and in the general population in Africa, may play a significant role (Hendriksen et al., 2009; Matovu \& Makumbi, 2007).

Our paper reviews the HIV risks associated with PWID in sub-Saharan Africa and estimates of HIV prevalence in this population. Our findings demonstrate that the risks associated with this population put recent advances that have decreased new HIV infections in the region at grave risk. If prevention efforts fail to address the particular needs of this population, those successes may be lost (WHO, 2006).

\section{Methods}

We searched PubMed using the terms injection drug use and sub-Saharan Africa and HIV risk, limited to 2005-2012, which yielded 36 articles, nine of which directly addressed HIV risks among PWID in the region. Searching the terms stigma and HIV testing and subSaharan Africa and injection drug use yielded no results. A second search omitting injection drug use revealed four articles on stigma and HIV-test decision-making, and stigma among PWID in sub-Saharan Africa. Examining the references in the literature found via the PubMed searches showed literature on HIV and PWID in sub-Saharan Africa unavailable through PubMed or other Internet databases. We contacted the Editors of the African Journal of Drug and Alcohol Studies for eight pertinent articles. Individual country names were searched in PubMed with the term injection drug use, yielding no results. Of the 47 countries that comprise the sub-Saharan African region, we found articles on IDU and PWID for eight countries: Ghana, Kenya, Malawi, Mauritius, Nigeria, South Africa, Tanzania, and Zanzibar.

\section{Results}

\section{Risks Related to Drug Use}

Estimates of the prevalence of PWID in sub-Saharan Africa are not widely available, except for South Africa and Nigeria (Mathers et al., 2008). From the limited research that has focused on PWID in the region, it appeared that extremely high-risk practices were associated with drug use. Timpson and colleagues (2006) described the risk behaviors of 319 PWID in Dar es Salaam, Tanzania. More than 35\% of the sample self-reported having injected with a syringe previously used by another person at least once in the previous month, and $45 \%$ had shared used syringes with others in that same time period. Williams 
and colleagues (2009) found that $31 \%$ of their Tanzanian sample of PWID reported injecting with a syringe used by someone else, and $41 \%$ had given their used syringes to another person for use. In Mauritius, where almost 100\% of new HIV infections occur among PWID, 50\% of participants reported syringe sharing (Abdool, Sulluman, \& Dhannoo, 2006). Among 239 injection heroin users in South Africa, 89\% had engaged in syringe sharing at some point during their injecting careers (Pluddeman, Parry, Flisher, \& Jordaan, 2008). Nigeria, Kenya, Ghana, and Zanzibar all reported similar high rates of syringe sharing (Table 2; Adeji et al., 2008; Adelekan \& Lawal, 2006; Beckerleg et al., 2006; Dahoma et al., 2006; Timpson et al., 2006). In Tanzania, PWID reported gathering in groups of at least four to pool money to purchase, prepare, and share drugs (McCurdy, Williams, Kilonzo, Ross, \& Leshabari, 2005b). Beckerleg and colleagues (2006) reported that most (89\%) PWID in Kenya also described injecting in groups, and more than a quarter (27.6\%) of those who reported distributive syringe sharing (sharing used syringes with others) reported being infected with HIV. Most syringes available in sub-Saharan Africa have large-bore needles. These become dulled through frequent reuse, increasing the amount of blood that can collect in the needle as compared to the smaller needles used by PWID in the United States and Europe (Paintsil, He, Peters, Lindenbach, \& Heimer, 2010). Participants also reported sharing ancillary injection equipment such as cookers, cotton filters, and rinse water. Sharing ancillary equipment can potentially spread HIV and other blood-borne viral infections (Paintsil et al., 2010).

Drugs in sub-Saharan Africa are often purchased as a package, which may include used syringes (Dahoma et al., 2006; Parry \& Pithey, 2006; Reid, 2009). Few PWID know the origin of the syringes they purchase and cannot be sure if they are sterile or previously used (Beckerleg et al., 2006; McCurdy et al., 2006; Parry, Carney, Petersen, Dewing, \& Needle, 2009), thus, rates of reuse may be even higher than reported. To compound this problem, PWID report being unable to purchase new syringes at pharmacies, although they are available legally (Pluddeman et al., 2008; Reid, 2009).

Backloading and flashblood are two specific high-risk activities that enhance the risk of transmitting HIV or other blood-borne viral infections (McCurdy, Williams, Ross, Kilonzo, \& Leshabari, 2005a) and are practiced among PWID in sub-Saharan Africa, particularly Tanzania and Zanzibar (Dahoma et al., 2006; McCurdy et al., 2005b; Ross, McCurdy, Kilonzo, Williams, \& Leshabari, 2008). Backloading, a means of sharing drugs, refers to the process of preparing the drug in one syringe and then injecting a portion of the preparation into another syringe. Although backloading can be done in a sterile manner, it also can serve as a mechanism for disease transmission. Flashblood, a practice first reported in 2005 and unique to sub-Saharan Africa, involves injecting heroin, then drawing out as much as $3 \mathrm{cc}$ of blood into the syringe, and passing the syringe filled with blood to another injector for injecting (McCurdy et al., 2005b). It is reportedly used to prevent opiate withdrawal symptoms, and practiced by as many as 10\% of IDU in Tanzania and Zanzibar (Dahoma et al., 2006; Williams et al., 2007). Both of these practices, which involve direct contact with blood, underscore risks taken by PWID in sub-Saharan Africa; HIV transmission through blood exposure is up to 100 times higher than from sexual contact (Gisselquist, 2002).

\section{Injecting Context}

Research conducted in Tanzania, Zanzibar, and South Africa has described the social spaces in which drugs are injected and the associated risks. McCurdy and colleagues (2005a) and Ross and colleagues (2008) described mageto, the equivalent of shooting galleries, in Tanzania, where PWID go to inject drugs. Mageto vary; some are simply free places for PWID to gather and use, others are accessed only by paying an entrance fee, and still others offer "packages" where a user can purchase drugs and syringes and even have drugs administered. Moreover, multiple studies describe how PWID will leave their syringes at a 
mageto or gallery for "safekeeping" due to tough laws against being caught holding a used syringe (Dahoma et al., 2006; Parry et al., 2009; Ross et al., 2008; Timpson et al., 2006). Many PWID reported that they did not share their syringes but in fact did not know what happened to needles left unattended.

Prisons are another sphere where PWID can engage in high-risk injecting. A2008 study in Ghana found that $35 \%$ of inmates reported a history of IDU; $71.5 \%$ reported ever sharing needles (Adeji et al., 2008). The prevalence of HIV infection was 5.9\% among the inmates and $4.9 \%$ among prison officers, as compared to the overall $1.9 \%$ HIV prevalence in the general population of Ghana (UNAIDS, 2008). Reports from Zambia (Moszynski, 2010), Zimbabwe (Alexander, 2009), South Africa (Essuon et al., 2009), and Nigeria (Adoga et al., 2009) have suggested similar high-risk prison populations. Many inmates enter corrections facilities already infected with HIV, creating heightened opportunities for transmission with high-risk behaviors and elevated HIV prevalence in prisons (Dolan, Kite, Black, Aceijas, \& Stimson 2007). These risks are not limited to prison populations. Former inmates put outside communities at risk as well when they are released without proper linkage to HIV care, and families are not educated about the risks incarceration can pose (Dolan et al., 2007). Although the problem of transition between prisons and communities is not unique to subSaharan Africa, it is an important consideration of risk in the region.

\section{Access to Treatment}

SEPs reduce HIV transmission and are linked to reductions in self-reported injecting risk behavior (Palmateer et al., 2010). Despite this, sub-Saharan Africa has the lowest rate of clean syringe distribution in the world, with an estimated 0.1 clean syringes distributed per injector per year (Mathers et al., 2010). Mauritius is the only country in the region that has a government-sanctioned SEP program (Reid, 2009). Pharmacy syringe sales can also have positive impacts on injecting risk behavior (Palmateer et al., 2010) and are legal throughout sub-Saharan African nations. Nevertheless, PWID in Tanzania and South Africa have reported being denied syringe access at pharmacies (Pluddeman et al., 2008; Reid, 2009). Most countries in sub-Saharan Africa focus on harsh legal penalties for drug use (Affinnih, 2002). The consequences of these policies not only increase the stigma associated with drug use, further marginalizing this population, but also restrict access to drug treatment and services (Affinnih, 2002).

While harm-reduction policies can potentially reduce risks related to HIV transmission for PWID, the most effective prevention is cessation of injecting and its associated blood exposures (UNAIDS, 2007). Drug treatment programs, however, are scarce and costly in sub-Saharan Africa (Stimson et al., 2006; Wechsberg et al., 2009). For example, in 2007 there were five drug treatment programs in Kenya, which mostly relied on inconsistent volunteer workers and provided no services for women (Sullivan, Levine, Charwarski, Schottenfeld, \& Fiellin, 2007). In South Africa, in a study of 506 female drug users, less than $20 \%$ reported any awareness of drug treatment programs. Many PWID who were aware of drug treatment services reported that access to publicly funded treatment was difficult and lengthy, while private drug treatment programs were unaffordable (Parry, Petersen, Carney, $\&$ Needle, 2010). Effective opiate substitution therapies, such as methadone and buprenorphine, have been virtually unavailable in the region (Mathers et al., 2010; Parry et al., 2010). The only countries in sub-Saharan Africa that offered some type of opioid substitution program were Kenya, Mauritius, Senegal, and South Africa (Mathers et al., 2010). Some peer-based recovery programs, such as Narcotics Anonymous, existed in Kenya, South Africa, and Zanzibar (Dahoma et al., 2006; Sullivan et al., 2007; Wechsberg et al., 2009). The limited services in the region, coupled with the criminalization of drug use, do little to reduce HIV risks faced by PWID in sub-Saharan Africa and do not meet the global recommendations of the WHO, UNODCP, and UNAIDS (2008). The most effective 
programs aimed at reducing HIV risks for PWID co-locate HIV prevention services with other services for drug users (WHO, 2006).

\section{Risks Related to Sexual Behavior}

The HIV risk of PWID in sub-Saharan Africa is not only related to drug use but also to concurrent sexual risks, including high rates of transactional sex (trading sex for money or drugs), multiple sex partners, and low rates of condom use (Table 3; Needle et al., 2006; Reid, 2009). Throughout the region, 70\%-90\% of females who inject drugs also engage in transactional sex (Dahoma et al., 2006; McCurdy et al., 2006; Ross et al., 2008; Wechsberg et al., 2009; Williams et al., 2009; Williams et al., 2007). In Mauritius, $74.5 \%$ of female IDU report engaging in transactional sex (Abdool et al., 2006). In Tanzania, 85\%-96\% of female PWID engage in transactional sex work (Timpson et al., 2006; Williams et al., 2007; Williams et al., 2009). Male PWID have also reported transactional sex activities (Dahoma et al., 2006; Hedden, Whitaker, Floyd, \& Latimer, 2009). While a small percentage (1.5\%) of males in Tanzania reported engaging in transactional sex (Williams et al., 2009), more than 52\% of male PWID in a South African sample reported a history of transactional sex (Hedden et al., 2009). Even in PWID who do not report sex work, sexual practices are risky. Dahoma and colleagues (2006) reported that male PWID in Zanzibar engaged in high-risk sexual practices such as group anal sex and sharing injecting equipment between sex and injecting partners.

While $61 \%$ of 385 PWID in a South African study reported condom use at last sexual encounter (Hedden et al., 2009), an extremely high percentage for any group, these results were not replicated in other countries. In Mauritius, $77 \%$ of transactional sex workers who injected drugs reported never using a condom with their regular sex partners, and one quarter reported never using condoms with clients (Abdool et al., 2006). In Tanzania, among PWID engaged in transactional sex work, half (49\%) reported never using a condom in the previous 30 days; only 23\% reported always using condoms (Williams et al., 2009). This sample had reported large numbers of sex partners, ranging from 1-300 in the previous 30 days, with more than $10 \%$ of subjects reporting 60 or more partners. In Nigeria, fewer than $20 \%$ of subjects interviewed reported occasionally or always using condoms in the previous 6 months (Adelekan \& Lawal, 2006). The concurrent risks of IDU, transactional sex work, and infrequent condom use clearly compound HIV risks in this population.

\section{Gender Differences}

Due to the significantly higher rates of transactional sex work by female PWID, coupled with low rates of condom use, HIV risks are potentially much higher for females who inject drugs than for males. In Tanzania, female PWID have reported as many as 12 times the number of sexual partners as males, as well as low condom usage (Williams et al., 2007). Transactional sex work, however, also provides economic freedom for women. In Tanzania, females were more likely to purchase and use drugs alone than males (Williams et al., 2007). Males, on the other hand, while less likely to engage in the risks related to transactional sex, were more likely to share drugs and injection equipment, due to less economic independence (Hedden et al., 2009; Ross et al., 2008; Williams et al., 2007). Although most subjects studied in the reviewed articles were male, females in many of these samples were two to four times more likely to be infected with HIV (Aceijas, Friedman, Cooper, Stimson, \& Hickman, 2006; Adelekan \& Lawal, 2006; Hedden et al., 2009; Williams et al., 2007).

\section{HIV Prevalence, Knowledge, Stigma, and Testing Uptake}

Relatively little is known about HIV prevalence in PWID in sub-Saharan Africa. South Africa is one of the only countries with systematic surveillance of IDU and HIV infection 
(Mathers et al., 2008; Needle et al., 2006). Data from other countries are limited by lack of systematic sampling, small sample sizes, and self-reported HIV infection. HIV testing is often refused and, as a result, few studies have reliable HIV data and none have reported HIV incidence in the region (Mathers et al., 2008).

Despite this, evidence indicates a potential HIV epidemic in PWID in sub-Saharan Africa. The extremely high proportions of PWID who are infected with HIV range from 5\% in Nigeria (Adelekan \& Lawal, 2006) to near 50\% in Tanzania (Williams et al., 2009). For comparison, in Russia, approximately $40 \%$ of PWID are infected with HIV (Mathers et al., 2008).

In sub-Saharan Africa, the high proportion of PWID who are also PLWH is coupled with a lack of knowledge about the risks associated with drug use. In a sample of 508 drug users (38.9\% self-reported PWID), Dahoma and colleagues (2006) showed that fewer than 50\% of subjects in Zanzibar could relate any negative health consequences to drug use. In Nigeria, only $25 \%$ of IDU reported an understanding of the HIV risks related to use (Adelekan \& Lawal, 2006). In addition to lack of knowledge about risks associated with IDU, fear of getting tested and receiving a diagnosis of HIV impacted rates of testing (Hendriksen et al., 2009; Matovu \& Makumbi, 2007; Meiberg et al., 2008).

Stigma, a complex process of negatively labeling people who are "different," resulting in devaluation and discrimination, has been widely implicated in reluctance to get tested for HIV (Hendriksen et al., 2009; Matovu \& Makumbi, 2007; Meiberg et al., 2008). Lack of knowledge about HIV transmission, belief that an HIV diagnosis meant immediate death, and the fear of results not being confidential, all contributed to low rates of HIV testing (Meiberg et al., 2008). Fears of the impact an HIV diagnosis might have on family and community also contributed to a lack of testing uptake (Hendriksen et al., 2009). There is a great deal of stigma related to being a PWID, and the fear of adding the burden of HIVrelated stigma could also be a restrictive factor for PWID to seek HIV testing (Parry et al., 2010). Female PWID, in large part due to HIV testing in antenatal clinics, are far more likely to have been tested for HIV and have more knowledge about HIV risk than men (Hendriksen et al., 2009). However, as males account for 66\%-93\% of all PWID in subSaharan Africa, the vast majority of PWID in the region are not receiving education about risks or individualized counseling, nor are they learning their HIV status (Aceijas et al., 2006). This significant gap can have devastating consequences, as has been witnessed in other parts of the world. Ignoring the needs of PWID in sub-Saharan Africa may decimate the gains that have been made in the fight against HIV.

\section{Discussion}

PWID in sub-Saharan Africa not only suffer from negative consequences related to drug use, injection behaviors, and addiction, they also are at high risk of HIV infection. Risk exposures are prevalent, and access to drug use prevention and treatment services is limited (Mathers et al., 2010). Drug treatment is largely unavailable and HIV prevention services do not come close to meeting demands (Mathers et al., 2010). While non-governmental organizations have started to address some of the needs of PWID (Mathers et al., 2010), government responses have been, for the most part, weak. With the exception of Mauritius, most countries are resistant to harm-reduction policies and instead use imprisonment as a deterrent. These policies are unlikely to deter a potentially expanding epidemic. Targeted interventions are needed to increase awareness of risk and access to clean syringes and drug treatment programs. Promoting HIV testing uptake for PWID is an important means to access this hidden population and provide necessary linkages to care (WHO, 2006; UNAIDS, 2007). However, the illicit nature of drug use and social stigma need to be 
addressed in order to increase HIV testing and awareness of injecting risk. Engaging current and former PWID to help develop and implement interventions may be an effective way to reach this hidden population. Further, utilizing peer education may promote awareness of the risks associated with IDU and improve testing uptake.

High-risk sexual exposures in PWID also increase risk for HIV for non-injecting sexual partners. Targeted and comprehensive risk reduction programs need to address both injecting and sexual risks, especially for PWID engaged in transactional sex. Other efforts intended to reduce the spread of HIV through sexual contact may be undermined if this critical juncture of sex and drugs is ignored.

The dearth of research in this field leaves many gaps and unanswered questions. Research is urgently needed to provide accurate estimates of IDU in all 47 countries that comprise subSaharan Africa as well as estimates of HIV prevalence and incidence. Data on other bloodborne infections, such as hepatitis B and C, which are prevalent in PWID in other parts of the world, would also be informative in the context of sub-Saharan Africa (Aceijas et al., 2006). Co-infection increases morbidity, which further increases the health burden (France de Bravo et al., 2008).

Studies are also needed to examine specific interventions in order to assure effective prevention programs aimed at reducing HIV risk and transmission for PWID in sub-Saharan Africa. Due to the heterogeneity of cultures, risk behaviors, and other differences such as gender, policies, and structural factors, it is unlikely that a single intervention would be successful for all IDU populations in every sub-Saharan African country. Therefore, comprehensive strategies that include a range of interventions tailored to the needs of the most at-risk PWID communities are required.

\section{Conclusion}

Evidence suggests extremely high rates of injecting risk behaviors, sexual risk behavior, and HIV prevalence in drug injecting populations in sub-Saharan Africa, yet little access to information, sterile equipment, or HIV testing exists. Our review has identified gaps in information, disturbing trends, and an urgent need for a large-scale rollout of communityspecific responses. Recent gains in the fight against HIV in sub-Saharan Africa are at risk if the needs of this highly marginalized population are ignored. Policymakers and health care providers need to address the burgeoning HIV epidemic in PWID in sub-Saharan Africa with great urgency.

\section{References}

Abdool R, Sulluman F, Dhannoo M. The injecting drug use and HIV/AIDS nexus in the republic of Mauritius. African Journal of Drug \& Alcohol Studies. 2006; 5(2):108-116.

Aceijas C, Friedman S, Cooper H, Stimson G, Hickman M. Estimates of injecting drug users at the national and local level in developing and transitional countries, and gender and age distribution. Sexually Transmitted Infections. 2006; 82(4):iii10-iii17. http://dx.doi.org/10.1136/sti. 2005.019471. [PubMed: 16735287]

Adeji A, Armah H, Gbagbo F, Ampofo W, Boamah I, Adu-Gyamfi C, Mensah G. Correlates of HIV, $\mathrm{HBV}, \mathrm{HCV}$ and syphilis infections among prison inmates and officers in Ghana: A national multicenter study. BMC Infectious Diseases. 2008; 8:33. http://dx.doi.org/10.1186/1471-2334-8-33. [PubMed: 18328097]

Adelekan M, Lawal R. Drug use and HIV infection in Nigeria: A review of recent findings. African Journal of Drug \& Alcohol Studies. 2006; 5(2):118-129.

Adoga M, Banwat E, Forbi J, Nimzing L, Pam C, Gyar SD, et al. Agwale SM. Human immunodeficiency virus, hepatitis B virus and hepatitis $C$ virus: Seroprevalence, co-infection and 
risk factors among prison inmates in Nasarawa State, Nigeria. Journal of Infections in Developing Countries. 2009; 3(7):539-547.

Affinnih Y. Revisiting sub-Saharan African countries' drug problems: Health, social, economic costs, and drug control policy. Substance Use \& Misuse. 2002; 37(3):265-290. http://dx.doi.org/10.1081/ JA-120002479. [PubMed: 11913904]

Alexander J. Death and disease in Zimbabwe's prisons. Lancet. 2009; 373(9668):995-996. http:// dx.doi.org/10.1016/S0140-6736(09)60592-4. [PubMed: 19330896]

Beckerleg S, Telfer M, Sadiq A. A rapid assessment of heroin use in Mombasa, Kenya. Substance Use \& Misuse. 2006; 41(6\&7):1029-1044. http://dx.doi.org/10.1080/10826080600667193. [PubMed: 16809185]

Bisika T, Konyani S, Chamangwana I, Khanyizira G. An epidemiologic study of drug abuse and HIV and AIDS in Malawi. African Journal of Drug \& Alcohol Studies. 2008; 7(2):81-88.

Dahoma M, Salim A, Abdool R, Juma S, Yahya B, Shaka S, et al. Kibuka T. HIV and substance abuse: The dual epidemics challenging Zanzibar. African Journal of Drug \& Alcohol Studies. 2006; 5(2):130-139.

Dolan K, Kite B, Black E, Aceijas C, Stimson G. HIV in prison in low-income and middle-income countries. Lancet. 2007; 7(1):32-41. doi:1016/S1473-3099(06)70685-5.

Essuon A, Simmons D, Stephens T, Richter D, Lindley L, Braithwaite R. Transient populations: Linking HIV, migrant workers, and South African male inmates. Journal of Health Care of the Poor \& Underserved. 2009; 20(2 Suppl):40-52.

France de Bravo, B.; Curtis, M.; Eagan, E.; Korpivaara, A.; Kramer, W.; Pinkham, S.; et al. Wolfe, D. Harm reduction developments 2008: Countries with injection-driven HIV epidemics. 2008. Retrieved from http://www.soros.org/sites/default/files/developments_20080304.pdf

Gisselquist D. Estimating HIV-1 transmission efficiency through unsafe medical injections. International Journal of STDs and AIDS. 2002; 13:152-159. http://dx.doi.org/ 10.1258/0956462021924820.

Hedden S, Whitaker D, Floyd L, Latimer W. Gender differences in the prevalence and behavioral risk factors of HIV in South African drug users. AIDS Behavior. 2009; 13:288-296. http://dx.doi.org/ 10.1007/s10461-008-9467-0. [PubMed: 18850265]

Hendriksen E, Hlubinka D, Chariyalertsak S, Chingono A, Gray G, Mbwambo J, et al. Coates T. Keep talking about it: HIV/AIDS-related communication and prior HIV testing in Tanzania, Zimbabwe, South Africa and Thailand. AIDS Behavior. 2009; 13(6):1213-1221. http://dx.doi.org/10.1007/ s10461-009-9608-0. [PubMed: 19760154]

Joint United Nations Programme on HIV/AIDS. Injecting drug use: Focused HIV prevention works. 2007. Retrieved from http://www.unaids.org/en/Resources/PressCentre/Featurestories/2007/May/ 20070511BPHighcoveragesites/

Joint United Nations Programme on HIV/AIDS. Epidemiological fact sheet on HIV and AIDS core data on epidemiology and response. Ghana; 2008. Retrieved from http://apps.who.int/globalatlas/ predefinedReports/EFS2008/full/EFS2008_GH.pdf

Mathers B, Degenhardt L, Ali H, Wiessing L, Hickman M, Mattick R, et al. Strathdee S. HIV prevention, treatment and care services for people who inject drugs: A systematic review of global, regional and national coverage. Lancet. 2010; 375:1014-1028. doi: 1016/S0140-6736(10)60232-2. [PubMed: 20189638]

Mathers B, Degenhardt L, Philips B, Wiessing L, Hickman M, Strathdee S, et al. Mattick R. Global epidemiology of injecting drug use and HIV among people who inject drugs: A systematic review. Lancet. 2008; 371:1733-1745. http://dx.doi.org/10.1016/S0140-6736(08)61311-2. [PubMed: 18502283]

Matovu J, Makumbi F. Expanding access to voluntary HIV counselling and testing in sub-Saharan Africa: Alternative aproaches for improving uptake, 2001-2007. Tropical Medicine and International Health. 2007; 12(11):1315-1322. http://dx.doi.org/10.1111/j. 1365-3156.2007.01923.x. [PubMed: 17949401]

McCurdy S, Ross M, Kilonzo G, Leshabari M, Williams M. HIV/AIDS and injection drug use in the neighborhoods of Dar es Salaam, Tanzania. Drug and Alcohol Dependence. 2006; 82(Suppl 1):S23-S27. doi: 0.1016/S0376-8716(06)80004-9. [PubMed: 16769441] 
McCurdy S, Williams M, Kilonzo G, Ross M, Leshabari M. Heroin and HIV risk in Dar es Salaam, Tanzania: Youth hangouts, mageto and injecting practices. AIDS Care. 2005a; 17(Suppl 1):S65S76. http://dx.doi.org/10.1080/09540120500120930. [PubMed: 16096119]

McCurdy S, Williams M, Ross M, Kilonzo G, Leshabari M. A theme issue by, for and about Africa: New injecting practices increases HIV risk among drug users in Tanzania. British Medical Journal. 2005b; 331(7519):778. http://dx.doi.org/10.1136/bmj.331.7519. [PubMed: 16195302]

Meiberg A, Bos A, Onya H, Schaalma H. Fear of stigmatization as a barrier to voluntary HIV counselling and testing in South Africa. East African Journal of Public Health. 2008; 5(2):49-54. [PubMed: 19024410]

Montaner J, Lima V, Barrios R, Yip B, Wood E, Kerr T, et al. Kendall P. Association of highly active antiretroviral therapy coverage, population viral load, and yearly new HIV diagnoses in British Columbia, Canada: A population-based study. Lancet. 2010; 376:532-539. http://dx.doi.org/ 10.1016/S0140-6736(10)60936-1. [PubMed: 20638713]

Moszynski P. Zambian prisons "threaten public health" because of high rates of TB and HIV. British Medical Journal. 2010; 340:c2225. http://dx.doi.org/10.1136/bmj.c2225. [PubMed: 20423968]

Needle R, Kroeger K, Belani H, Hegle J. Substance abuse and HIV in sub-Saharan Africa: Introductiontothe special issue. African Journal of Drug \& Alcohol Studies. 2006; 5(2):83-94.

Paintsil E, He H, Peters C, Lindenbach B, Heimer R. Survival of hepatitis C virus in syringes: Implications for transmisison among injection drug users. Journal of Infectious Diseases. 2010; 202:984-990. http://dx.doi.org/10.1097/01.ede.0000135170.54913.9d. [PubMed: 20726768]

Palmateer N, Kimber J, Hickman M, Hutchinson S, Rhodes T, Goldberg D. Evidence for the effectiveness of sterile injecting equipment provision in preventing hepatitis $\mathrm{C}$ and human immunodeficiency virus transmission among injecting drug users: A review of reviews. Addiction. 2010; 105(5):860-861. http://dx.doi.org/10.1111/j.1360-0443.2009.02888.x. [PubMed: 20402974]

Parry C, Carney T, Petersen P, Dewing S, Needle R. HIV-risk behavior among injecting or noninjecting drug users in Cape Town, Pretoria, and Durban, South Africa. Substance Use \& Misuse. 2009; 44(6):886-904. http://dx.doi.org/10.1080/10826080802487028. [PubMed: 19444728]

Parry C, Petersen P, Carney T, Needle R. Opportunities for enhancing and integrating HIV and drug services for drug using vulnerable populations in South Africa. International Journal of Drug Policy. 2010; 21:289-295. doi:1016/j.drugpo.2009.11.008. [PubMed: 20036527]

Parry C, Pithey A. Risk behaviour and HIV among drug using populations in South Africa. African Journal of Drug \& Alcohol Studies. 2006; 5(2):140-157.

Pluddeman A, Parry C, Flisher A, Jordaan E. Heroin users in Cape Town, South Africa: Injecting practices, HIV-related risk behaviors, and other health consequences. Journal of Psychoactive Drugs. 2008; 40(3):273-279. doi:1016/j.drugpo.2009.11.008. [PubMed: 19004419]

Reid S. Injection drug use, unsafe medical injections and HIV in Africa: A systematic review. Harm Reduction. 2009; 6(24) http://dx.doi.org/10.1186/1477-7517-6-24.

Ross M, McCurdy S, Kilonzo G, Williams M, Leshabari M. Drug use careers and blood-borne pathogen risk behavior in male and female Tanzanian heroin injectors. American Journal of Tropical Medicine. 2008; 79(3):338-343.

Stimson G, Fitch C, DesJarlais D, Poznyak V, Perlis T, Oppenheimer E, Rhodes T. Rapid assessment and response studies of injection drug use: Knowledge gain, capacity building, and intervention development in a multisite study. American Journal of Public Health. 2006; 96(2):288-295. http:// dx.doi.org/10.2105/AJPH.2003.035899. [PubMed: 16380578]

Sullivan L, Levine B, Charwarski M, Schottenfeld R, Fiellin D. Addiction and HIV in Kenya: A description of treatment serivces and integration. African Journal of Drug \& Alcohol Studies. 2007; 6(1):17-26.

Timpson S, McCurdy S, Leshabari M, Kilonzo G, Atkinson J, Msami A, Williams M. Substance abuse, HIV risk and HIV/AIDS in Tanzania. African Journal of Drug \& Alcohol Studies. 2006; 5(2):158-169.

United Nations Office for Drug Control and Crime Provention. World drug report 2011. 2011. Retrieved from http://www.unodc.org/unodc/en/frontpage/2011/June/wdr-2011--drug-marketsstable-but-consumption-of-synthetic-and-prescription-drugs-rises.html 
Wechsberg W, Wu L, Zule W, Parry C, Browne F, Luseno W, et al. Gentry A. Substance abuse, treatment needs and access among female sex workers and non-sex workers in Pretoria, South Africa. Substance Abuse Treatment, Prevention and Policy. 2009; 4(11) http://dx.doi.org/ 10.1186/1747-597X-4-11.

Williams M, McCurdy S, Atkinson J, Kilonzo G, Leshabari M, Ross M. Differences in HIV risk behaviors by gender in a sample of Tanzanian injection drug users. AIDS Behavior. 2007; 11:137144. http://dx.doi.org/10.1007/s10461-006-9102-x. [PubMed: 17004117]

Williams M, McCurdy S, Bowen A, Kilonzo G, Atkinson J, Ross M, Leshabari M. HIV seroprevalence in a sample of Tanzanian intravenous drug users. AIDS Education and Prevention. 2009; 21(5):474-483. http://dx.doi.org/10.1521/aeap.2009.21.5.474. [PubMed: 19842830]

World Health Organization. Treatment of injecting drug users with HIV/AIDS: Promoting access and optimizing services delivery. 2006. Retrieved from http://www.who.int/substance_abuse/ publications/treatment_idus_hiv_aids.pdf

World Health Organization, United Nations Office on Drugs and Crime, \& Joint United Nations Programme on HIV/AIDS. Technical guide for countries to set targets for universal access to HIV prevention, treatment and care for injecting drug users. 2008. Retrieved from http://

www.unodc.org/documents/hiv-aids/WHO\%20UNODC\%20UNAIDS\%20\%20IDU\%20Universal $\%$ 20Access\%20Target\%20Setting\%20Guide\%20-\%20FINAL\%20-\%20Feb\%2009.pdf 


\section{Clinical Considerations}

- People in sub-Saharan Africa seeking voluntary counseling and testing for HIV should be screened for drug use, particularly injection drug use (IDU).

- Health care providers working in sub-Saharan Africa need comprehensive training on screening and interventions for drug use.

- HIV prevention messages in sub-Saharan Africa need to address the risks related to IDU.

- Prevention counseling and interventions geared at people who inject drugs need to target both injection-related and sex-related HIV risks.

- Interventions for IDU should provide harm reduction-based solutions such as drug treatment (as opposed to criminal intervention), cognitive-based psychotherapeutic approaches, and syringe exchange programs. 


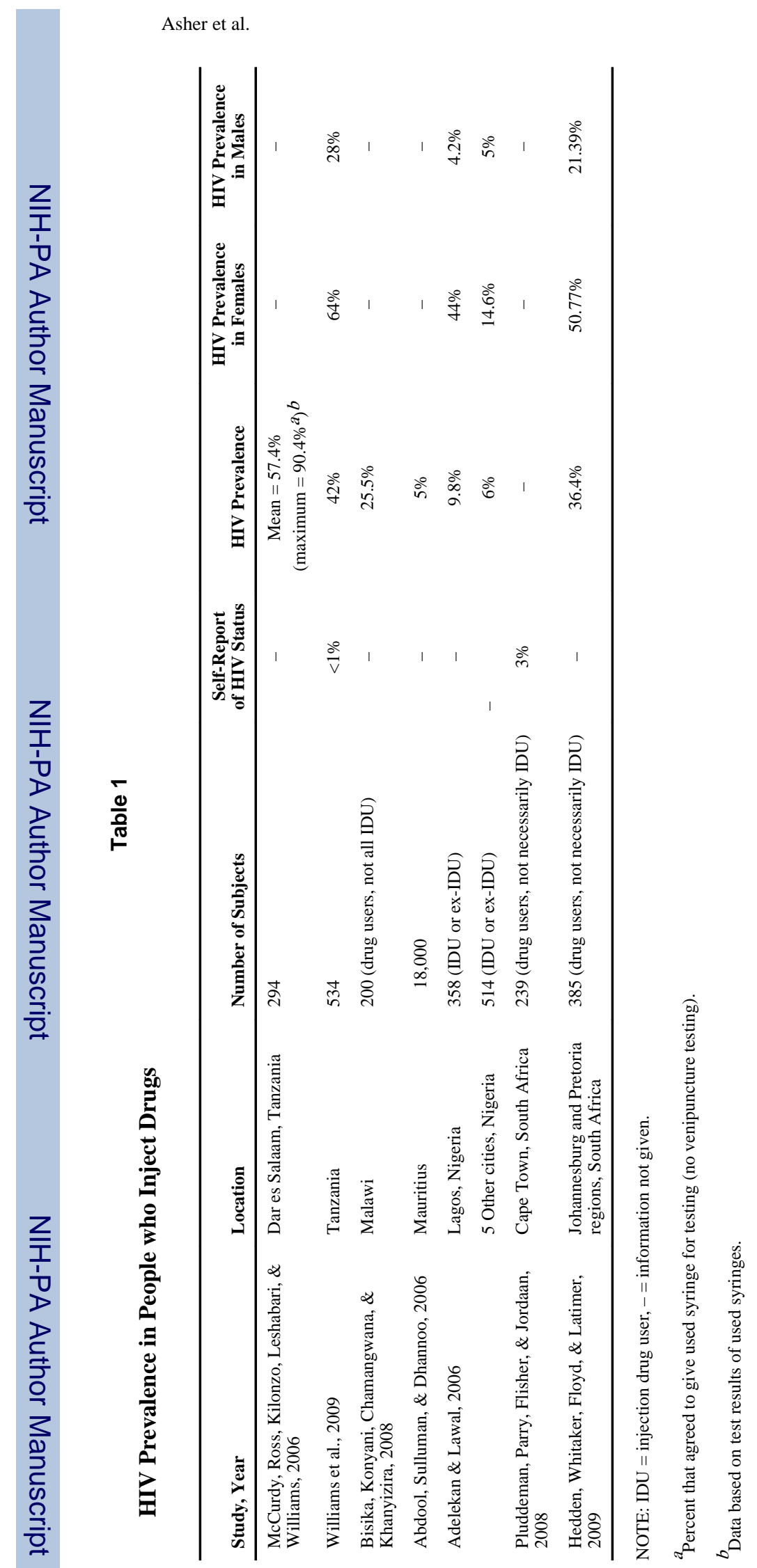

J Assoc Nurses AIDS Care. Author manuscript; available in PMC 2013 November 01. 
Table 2

Syringe Sharing Estimates by Country

\begin{tabular}{ll}
\hline Country & Estimated Prevalence of Syringe Sharing among PWID \\
\hline Ghana (Adeji et al., 2008) & $72.9 \%$ (ever) \\
Kenya (Sullivan, Levine, Charwarski, Schottenfeld, \& Fiellin, 2007) & $27 \%-81 \%$ (ever) \\
Mauritius (Abdool, Sulluman, \& Dhanoo, 2006) & $28 \%-52 \%$ (previous 6 months) \\
Nigeria (Adelekan \& Lawal, 2006) & $30 \%-50 \%$ (ever) \\
South Africa (Parry \& Pithey, 2006; Pluddeman, Parry, Flisher, \& Jordaan, 2008) & $67 \%-89 \%$ (previous 12 months) \\
Tanzania (Timpson et al., 2006; Williams et al., 2007; Williams et al., 2009) & $31 \%$ RSS (ever) \\
Zanzibar (Dahoma et al., 2006) & $41 \%$ DSS (ever) \\
\hline
\end{tabular}

NOTE: PWID = people who inject drugs, RSS = receptive syringe sharing, DSS = distributive syringe sharing. 
Table 3

People who Inject Drugs and Sexual Risk

\begin{tabular}{lll}
\hline Country & $\begin{array}{l}\text { Exchange Sex for } \\
\text { Money }\end{array}$ & $\begin{array}{l}\text { Sometimes, Occasional, Never } \\
\text { Condom Use }\end{array}$ \\
\hline Ghana (Adeji et al., 2008) & $5.3 \%$ & Not given \\
Kenya (Sullivan, Levine, Charwarski, Schottenfeld, \& Fiellin, 2007) & $17.4 \%$ & $87.7 \%$ (last encounter) \\
Mauritius (Abdool, Sulluman, \& Dhannoo, 2006) & Not given & $80 \%$ (ever) \\
Nigeria (Adelekan \& Lawal, 2006) & Not given & $80 \%$ (past 30 days) \\
$\begin{array}{l}\text { South Africa (Parry \& Pithey, 2006; Pluddeman, Parry, Flisher, \& Jordaan, } \\
\text { 2008) }\end{array}$ & $5.6 \%$ & $64 \%$ (ever) \\
$\begin{array}{l}\text { Tanzania (Timpson et al., 2006; Williams et al., 2007; Williams et al., } \\
\text { 2009) }\end{array}$ & $33 \%-85 \%$ & $60 \%-76 \%$ (ever) \\
Zanzibar (Dahoma, et al., 2006) & & \\
\hline
\end{tabular}

